\title{
Avaliação do Ambiente Sonoro e sua Integração com Aspectos Urbanísticos. Estudo de Caso: Bairro de Vila Isabel, Rio de Janeiro
}

FRANÇA Camilla Rocha, ROCHA Daniela Ribeiro da

Programa de Engenharia Urbana - PEU/POLI/UFRJ

Informações do Artigo

Histórico:

Recebimento: 26 Outubro 2018

Revisão: 21 Novembro 2018

Aprovação: 21 Dezembro 2018

Palavras-chave:

Ruído Urbano

Simulação Acústica

Uso do solo

\section{Resumo:}

O aumento da poluição sonora urbana, apesar de ser consequência direta de fatores como a morfologia urbana, o uso do solo e os sistemas de transportes adotados, ainda é negligenciado no planejamento urbano das cidades brasileiras. O ruído urbano, dependendo de seu nível sonoro e do tempo de exposição, pode causar inúmeros danos à saúde humana, inclusive irreversíveis. Nesse contexto, os números de reclamações relativas à perturbação do sossego em centros urbanos brasileiros são alarmantes. O presente estudo visa mapear os níveis de ruído em uma via de tráfego intenso na cidade do Rio de Janeiro, localizada em uma zona com ocupação residencial com escolas e hospitais, mas que também possui influência das atividades sonoras de uma escola de samba. Pretende-se determinar se a contribuição dessa fonte sonora é significativa no quadro de ruído da região, além de apontar se os níveis alcançados estão de acordo com o limitado pela legislação vigente e qual a reação esperada da população impactada.

\section{Introdução}

O crescimento dos centros urbanos e sua densificação se apresentam como tendência mundial: espera-se que $70 \%$ da população residam em ambientes urbanos até 2050 [1]. Especialmente nos países subdesenvolvidos, esse processo ocorre comumente de forma desordenada e representa um desafio à manutenção da qualidade de vida nas cidades.

Sob esse aspecto, a concentração das atividades econômicas e de ocupação populacional acentuaram as emissões de ruído, tornando esta a terceira maior fonte de poluição do planeta [2]. Conforme a Lei Brasileira $\mathrm{N}^{\circ}$ $6.938 / 81$, art. $3^{\circ}$, define-se por poluição sonora a degradação da qualidade ambiental resultante de atividades que direta ou indiretamente lancem matérias ou energia em desacordo com os padrões ambientais estabelecidos.

O nível de pressão sonora equivalente é uma quantidade utilizada para avaliar o incômodo sonoro, expressa em decibel - $d B$, relativo a uma pressão mínima audível de $20 \mu \mathrm{Pa}$. Segundo [3], o nível médio sonoro a que as pessoas podem ser expostas sem prejuízo a saúde é de $55 \mathrm{~dB}$. Níveis acima de $65 \mathrm{~dB}$ podem ter como consequência uma série de efeitos negativos que, além da perda de audição, podem provocar distúrbios no sono, doenças cardiovasculares, efeitos neuropsíquicos, estresse, irritabilidade, interferência na comunicação verbal, queda 
qualidade de atividades de trabalho e lazer [4, 5, 6].

Conforme aponta [7], o ruído constitui uma das principais causas de perturbação e, em geral, nas grandes cidades representa cerca de $70 \%$ das reclamações junto aos órgãos de controle ambiental. Dessa forma, a promoção de um ambiente sonoro "confortável" nos espaços urbanos deve ser uma preocupação no momento da definição das linhas estratégicas do uso do solo [8], e de demais políticas de planejamento urbano.

Nesse contexto, o objetivo do presente estudo é avaliar o cenário acústico do bairro de Vila Isabel, Rio de Janeiro, considerando seus aspectos urbanísticos, especialmente no que diz respeito à ocupação de sua principal via por receptores sonoros críticos (escolas e hospitais) e por potente fonte geradora de ruído, uma Escola de Samba. Além disso, será apontado se os níveis alcançados estão de acordo com o limitado pela legislação vigente e qual a reação esperada da população impactada.

\subsection{Planejamento Urbano e a Emissão de Ruídos}

No Brasil, a regulamentação sobre poluição sonora é dada pela Resolução CONAMA n 01/90, pelas normas técnicas da ABNT (NBR 10.151 e NBR 10.152) e pelas legislações federais, estaduais e municipais, conforme cada caso [9]. A partir do Plano Diretor, os municípios estabelecem o Zoneamento Urbano que define a permissão de atividades para cada tipo de uso de solo e consequente ocupação de cada zona. Com base nessa informação, são definidos os níveis de ruído aceitáveis para cada uma dessas.

Entretanto, dentro de uma área de uso designado, é comum haver atividades que exijam menores níveis de ruído, ditos receptores críticos, tais como hospitais e escolas. Além disso, nos grandes centros urbanos, tais edificações podem estar localizadas em vias principais e de tráfego intenso de veículos, o que torna mais desafiadora a tarefa de manter o ruído abaixo dos níveis recomendados.

Esses limites encontram-se apresentados na Tabela 1 de acordo com o uso do solo da região.

Tabela 1 - Nível de critério de avaliação NCA para ambientes externos, em dB.

\begin{tabular}{ccc}
\hline Tipos de Áreas & Diurno & Noturno \\
\hline $\begin{array}{c}\text { Sítiose fazendas } \\
\text { Residencial urbana ou de } \\
\text { hospitais ou de escolas }\end{array}$ & 40 & 35 \\
$\begin{array}{c}\text { Área mista, predominância } \\
\text { residencial }\end{array}$ & 55 & 50 \\
$\begin{array}{c}\text { Área mista, com vocação } \\
\text { comercial e administrativa } \\
\text { Área mista, com vocação } \\
\text { recreacional }\end{array}$ & 60 & 55 \\
$\begin{array}{c}\text { Área predominantemente } \\
\text { industrial }\end{array}$ & 70 & 65 \\
\hline
\end{tabular}

Fonte: NBR 10151 (2000).

Além disso, outros fatores contemplados no planejamento urbano influenciam a formação do cenário acústico das cidades e serão considerados no presente estudo de caso: a morfologia, o tráfego e a existência de mecanismos de atenuação sonora.

\subsubsection{Morfologia}

De acordo com [10], alguns aspectos morfológicos influem diretamente na propagação do som no meio urbano:

a malha viária, a divisão fundiária, a relação entre cheios e vazios, a tipologia dos edifícios (escala, volumetria, estilo) e, sobretudo, o modo como estes elementos se relacionam. Há que se destacar dentre esses fatores, a altura dos edifícios e os afastamentos entre as edificações. Apesar de usualmente restringidos pela legislação local, podem ocasionar a formação de corredores sonoros responsáveis pelo fenômeno de reverberação do som, ou seja, a reflexão de forma reiterada (Figura 1 ). 
Figura 1 - Espaço acústico aberto e fechado

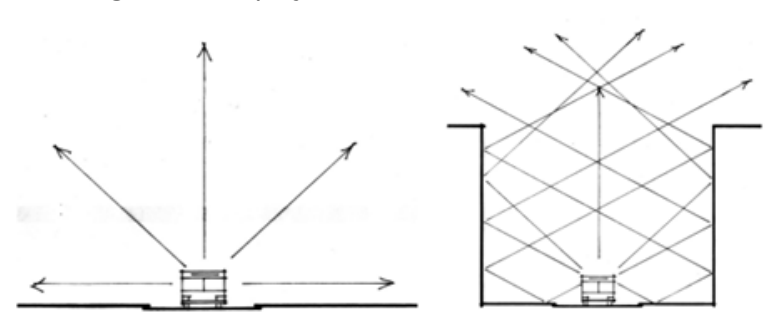

Fonte: NIEMEYER, M. L.; SANTOS, M. J. O. (2001)

\subsubsection{Tráfego}

Diversos estudos realizados em várias cidades revelam que o ruído de tráfego é o maior responsável para os níveis sonoros medidos e, consequentemente, a maior causa de incômodo em áreas urbanas [11, 12, 13].

Em relação ao planejamento com vistas à qualificação do ambiente urbano frente ao aumento massivo do número de veículos, [14] ressalta a importância da organização do tráfego, dando prioridade ao transporte público e ao pedestre, do planejamento das rodovias, corredores de tráfego, aeroportos, ferrovias a partir de medidas que protejam a população.

\subsubsection{Mecanismos urbanos de atenuação sonora}

Há ainda outros mecanismos urbanos que se apresentam como opção para mitigar os efeitos do ruído. Devido a sua capacidade de absorver ondas sonoras [15], a arborização vem sendo utilizada com o objetivo de combater a poluição sonora, formando o que se denomina "barreiras de contenção" [16].

É o caso também das ditas silent areas, usualmente praças ou parques, cuja criação e preservação vendo sendo encorajada na Europa desde a criação da Diretiva 2002/49/EC [17]. O objetivo dessas áreas seria promover a restauração sonora dos cidadãos, reduzindo os efeitos danosos do ruído na percepção dos usuários.

\section{Metodologia}

O método empregado para avaliação do ruído em área urbana foi adaptado de trabalhos semelhantes $[18,19,20]$, sendo necessária a construção de um modelo geométrico-acústico, cuja validação é feita por comparação com valores de níveis sonoros simulados e medidos em campo. Esse modelo considera as características viárias, de tráfego e morfológicas da região de estudo.

\section{1 Área de Estudo}

Um exemplo desta relação entre uso do solo e limites de ruído dentro de uma grande cidade é encontrado no bairro de Vila Isabel, localizado na cidade do Rio de Janeiro. O bairro encontra-se em uma macrozona de ocupação incentivada, em grande parte de uso misto (residencial e comercial), com predomínio do uso comercial ao longo de sua principal via, a Boulevard 28 de Setembro. As demais vias do bairro possuem predominantemente ocupação residencial.

Essa via é um importante meio de ligação entre o Centro da cidade e os bairros da Zona Norte, o que provoca um tráfego intenso de veículos ao longo do dia. No entanto, nela estão localizados alguns receptores críticos, ou seja, locais com maior restrição aos níveis de poluição sonora. Desses, foram selecionados para análise: um hospital universitário e duas escolas municipais, conforme mostrado na Figura 2 (ANEXO A).

Além disso, sendo a cidade reconhecida pela cultura do Samba, as escolas de samba e agremiações possuem áreas particulares espalhadas pelo território da cidade [21]. Nessa mesma avenida principal, está localizada uma escola de samba com capacidade para 11.000 pessoas e que recebe com frequência shows e ensaios (Figura 3).

A G.R.E.S Unidos de Vila Isabel vem sendo alvo de reclamações dos moradores devido ao ruído gerado, chegando a ser multada pelo poder público e fechada por ordem judicial em 2015.

Assim, a área estudada apresenta certa complexidade sonora, tanto com fontes de atuação constante como o tráfego, como a fonte pontual da escola de samba. Ademais, não apresenta grande arborização e/ou zonas de 
silêncio. As características urbanísticas encontradas estão listadas na Tabela 2.

Figura 3 - Localização da G.R.E.S Unidos de Vila Isabel no Bairro de Vila Isabel.

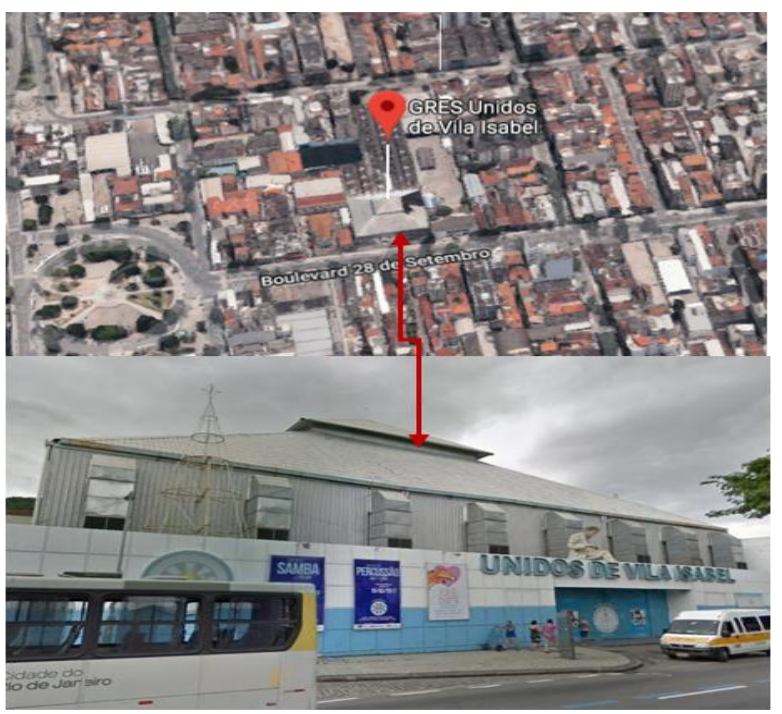

Fonte: Adaptado de Google Maps, 2018.

Tabela 2 - Área de estudo e localização dos receptores sonoros críticos na Boulevard 28 de Setembro

\begin{tabular}{|c|c|c|}
\hline Características & 28 de Setembro & $\begin{array}{l}\text { Vias do } \\
\text { Entorno }\end{array}$ \\
\hline Zoneamento & $\begin{array}{l}\text { Comercial/ } \\
\text { Residencial }\end{array}$ & $\begin{array}{c}\text { Residencia } \\
\text { I }\end{array}$ \\
\hline $\begin{array}{l}\text { Gabarito } \\
\text { Máximo } \\
\text { Permitido }\end{array}$ & 25 metros & Variável \\
\hline $\begin{array}{l}\text { Gabarito } \\
\text { Encontrado }\end{array}$ & $\begin{array}{l}\text { Variável - } \\
\text { prédios médios, } \\
\text { altos e casas }\end{array}$ & $\begin{array}{l}\text { Casase } \\
\text { prédios } \\
\text { baixos }\end{array}$ \\
\hline $\begin{array}{l}\text { Tráfego de } \\
\text { veículos }\end{array}$ & $\begin{array}{c}\text { Intenso - } \\
\text { Circulação de } \\
\text { linhas de ônibus } \\
\text { e } 4 \text { faixas de } \\
\text { rolamento }\end{array}$ & $\begin{array}{l}\text { Médio/ } \\
\text { Baixo }\end{array}$ \\
\hline $\begin{array}{l}\text { Receptores } \\
\text { Críticos }\end{array}$ & $\begin{array}{l}\text { Um hospital e } \\
\text { duas escolas da } \\
\text { rede pública }\end{array}$ & Escolas \\
\hline $\begin{array}{c}\text { Nível de } \\
\text { arborização }\end{array}$ & Baixo & $\begin{array}{l}\text { Baixo/ } \\
\text { Médio }\end{array}$ \\
\hline $\begin{array}{c}\text { Zonas de } \\
\text { silêncio } \\
\text { (parquese } \\
\text { praças } \\
\text { arborizadas) }\end{array}$ & Não há & Não há \\
\hline
\end{tabular}

Fonte: Autoras a partir de informações obtidas na Prefeitura do Rio de Janeiro, 2018.
2.2 Coleta de Dados, Modelagem e Simulação

O presente estudo se divide em duas análises: Situação (1) - avaliação dos níveis de ruído nos receptores críticos; e Situação (2) impacto da atuação da escola de samba no cenário acústico do bairro. Na Figura 4 estão apresentados os pontos de medição em campo, distribuídos espacialmente de maneira uniforme na área de análise (ANEXO B).

Foi elaborado um modelo geométrico da área de estudo que teve como base as plantas cadastrais pertencentes ao acervo do Instituto Municipal Pereira Passos (IPP). Com uso do software AutoCAD foi possível, a partir das bases cadastrais e auxílio da ferramenta Google Earth (2018), construir um modelo 3D representativo das edificações e das vias na área de estudo, ou seja, da morfologia encontrada.

No software Predictor-LimA, o modelo geométrico foi importado e foram inseridas as características acústicas, conforme a norma ISO 9613-2 (road). Para tal, fez-se necessário incluir informações sobre o tráfego nas vias, tais como o número de veículos por tipo (categorizados de forma simplificada em motocicletas, carros, ônibus e caminhões) e sua velocidade média. Esses dados foram levantados por meio da contagem de veículos durante o período de medição (entre 5 e 10 minutos) e extrapolados para o período de uma hora.

Durante o período de contagem de veículos, também foram medidos os níveis equivalentes de pressão sonora (LAeq) para validação do modelo acústico, conforme descrito na NBR 10.151/2000 [22]. Foi utilizado um sonômetro classe 2 (MSL1354) posicionado a 1,20 metros de altura em relação ao piso. Foi adotada a configuração de medição de nível de pressão sonora equivalente a ponderado em " $A$ " e resposta lenta (slow). A medição em cada ponto teve duração de três minutos, com períodos de amostragem a cada um segundo. 


\subsubsection{Situação (1) - Receptores Críticos}

Para o cálculo de nível sonoro equivalente nos receptores críticos, foi delimitada uma área retangular, de $1600 \mathrm{~m}$ de extensão por $300 \mathrm{~m}$ de largura, seguindo o eixo da via principal, composta por uma malha de pontos receptores na altura de 1,20 metros do piso e espaçamento de $25 \times 25 \mathrm{~m}$. A partir dessa modelagem, obtiveram-se como produto os valores correspondentes aos níveis de pressão sonora nos pontos receptores e o mapa preditivo do ruído da região.

As medições foram feitas em horário diurno, mais crítico do tráfego na via, entre 8:00 e 9:00 horas da manhã, em dia útil, sem qualquer evento atípico que pudesse causar alteração da situação comumente encontrada. Vale destacar que o horário escolhido para as medições contemplou o período de funcionamento tanto das escolas quanto do hospital.

Para as vias secundárias, mediu-se o tráfego em duas delas (Pontos E e G - Figura 4). Para as demais vias, por terem características semelhantes, adotou-se uma média dos veículos desses dois pontos. Os valores de nível equivalente (LAeq) obtidos com o medidor correspondem a uma média (ponderada por bandas de frequência) dos valores de pressão sonora a cada um segundo. O nível sonoro equivalente (LAeq), em $d B$, dado pela seguinte equação:

$$
\mathrm{L}_{\text {Aeq, }}=10 \log _{10}\left[\frac{1}{\mathrm{~T}} \int_{\mathrm{t}_{1}}^{\mathrm{t}_{1}+\mathrm{T}}\left(\frac{\mathrm{p}_{\mathrm{A}}(\mathrm{t})}{\mathrm{p}_{0}}\right)^{2} \mathrm{dt}\right]
$$

Onde $\mathrm{p}_{\mathrm{A}}(\mathrm{t})$ é a pressão instantânea, $\mathrm{p}_{0}$ é a pressão referência $(20 \mu \mathrm{Pa})$ e T o período de medição

\subsubsection{Situação (2) - Atuação da Escola de} Samba

Uma vez que o perfil acústico na região foi caracterizado e validado na Situação (1), para a Situação (2) foi feita apenas a etapa de medições em campo. Essas ocorreram em dois dias distintos, sendo um domingo durante um show de música e uma quarta-feira durante o ensaio semanal da bateria da escola.

Foram feitas medições em horários imediatamente anteriores ao início da atuação da fonte emissora em estudo a fim de caracterizar o ruído de fundo gerado pelo tráfego característico. Dessa forma, é possível avaliar exatamente o impacto causado pela escola de samba no cenário acústico.

É válido ressaltar que os pontos $L, M$ e $N$ (Figura 4) referem-se a uma vila residencial voltada para os fundos da quadra. $\mathrm{O}$ ponto $\mathrm{M}$ e $\mathrm{N}$ foram medidos internamente em uma das casas, no segundo pavimento a uma altura aproximada de $4,20 \mathrm{~m}$ do solo, sendo o primeiro na fachada e o segundo internamente com a esquadria fechada, com o objetivo de avaliar a capacidade de absorção das fachadas e determinar o nível de incômodo ao qual os moradores estão submetidos no interior daquela edificação.

\section{Resultados}

\subsection{Situação (1) - Receptores Críticos}

A fim de validar o modelo acústico produzido pelo software Predictor-LimA, os níveis obtidos por simulação foram comparados com os medidos em campo, conforme mostrado na Tabela 3.

Tabela 3 - Resultados Obtidos da Medição e da Simulação - Situação (A)

\begin{tabular}{|c|c|c|c|}
\hline Ponto & Uso & $\begin{array}{c}\mathrm{L}_{\text {Aeq }} \\
\text { Medido } \\
\text { em dB }\end{array}$ & $\begin{array}{c}\mathrm{L}_{\text {Aeq }} \\
\text { Simulado } \\
\text { em dB }\end{array}$ \\
\hline A & Comercial & 71 & 74 \\
\hline$B$ & Hospitalar & 71 & 75 \\
\hline C & Escolar & 73 & 74 \\
\hline$D$ & $\begin{array}{c}\text { Comercial/ } \\
\text { Recreacional }\end{array}$ & 76 & 75 \\
\hline$E$ & Residencial & 72 & 76 \\
\hline $\mathrm{F}$ & Comercial & 73 & 77 \\
\hline G & Residencial & 69 & 71 \\
\hline $\mathrm{H}$ & Escolar & 75 & 76 \\
\hline 1 & $\begin{array}{c}\text { Comercial/ } \\
\text { Recreacional }\end{array}$ & 73 & 75 \\
\hline
\end{tabular}

Fonte: Autoras, 2018 
As variações de até $3 \mathrm{~dB}$ encontradas em alguns pontos são esperadas nesse tipo de simulação, principalmente pela incerteza dos dados de entrada ocasionada pelos coeficientes de absorção dos pavimentos e das fachadas das edificações do entorno. Ademais, os modelos de cálculo de emissão de potência sonora das vias baseiam-se nas características de veículos europeus, que diferem dos brasileiros em diversos aspectos. Logo, o modelo mostrou-se válido.

Após as etapas de modelagem, de inserção dos dados de tráfego e de locação dos pontos receptores, o software Predictor-LimA gerou 0 mapa relativo ao período diurno (de 7:00 às 22:00 h), conforme apresentado na Figura 5. Pode-se observar que ao longo da via principal, o ruído encontra-se sempre acima de $75 \mathrm{~dB}$.

Figura 5 - Mapa preditivo diurno gerado pelo Predictor LimA.

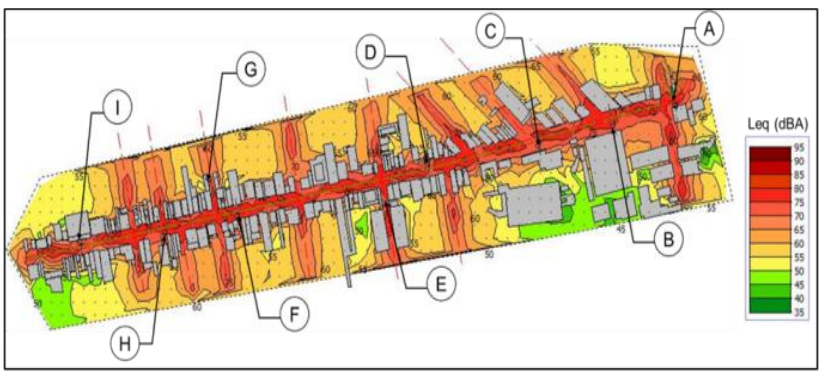

Fonte: Autoras, 2018.

Nas vias secundárias o ruído é menor, porém na faixa de $60 \mathrm{~dB}$ a $65 \mathrm{~dB}$. Poucas são as áreas onde o ruído encontra-se em níveis aceitáveis, segundo a NBR 10.151[22]. Isso ocorre nas áreas amarelas e verdes, principalmente devido ao efeito de barreira acústica promovido pelas edificações de maiores gabaritos, tais como o próprio hospital.

Entretanto, se por um lado o prédio do hospital serve de barreira para a sua fachada posterior e para áreas próximas, a fachada principal recebe a incidência de

A fim de analisar e ilustrar como a propagação do ruído se dá verticalmente ao redor dos principais receptores críticos, foram criadas duas seções verticais conforme indicado na Figura 6, que passam pelo Hospital Pedro
Ernesto (B) e pela Escola Argentina (A). Estes planos verticais possuem um maior nível de detalhe, composta por uma malha de receptores utilizando uma grade de $5 \times 5 \mathrm{~m}$. Os resultados são apresentados na Figura 7 (a) e (b).

Figura 6 - Detalhe da localização das seções transversais nos pontos críticos $\mathrm{B}$ e $\mathrm{C}$

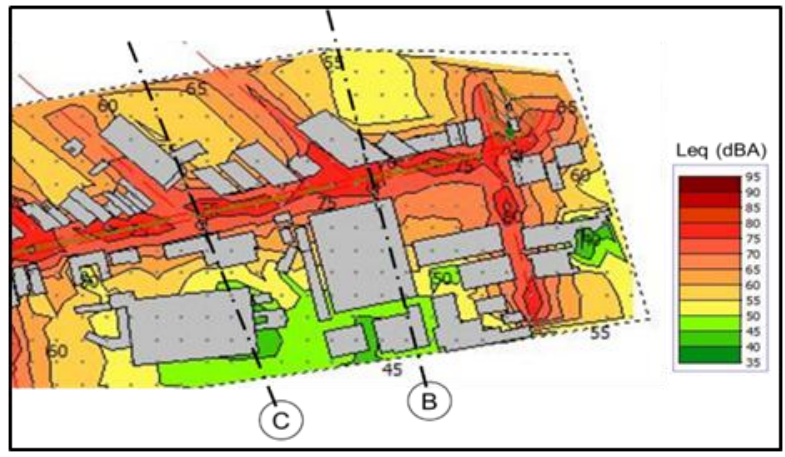

Fonte: Autoras, 2018

Figura 7 - Propagação vertical do som: (a) Ponto B Hospital Pedro Ernesto e (b) Ponto C - Escola Argentina.
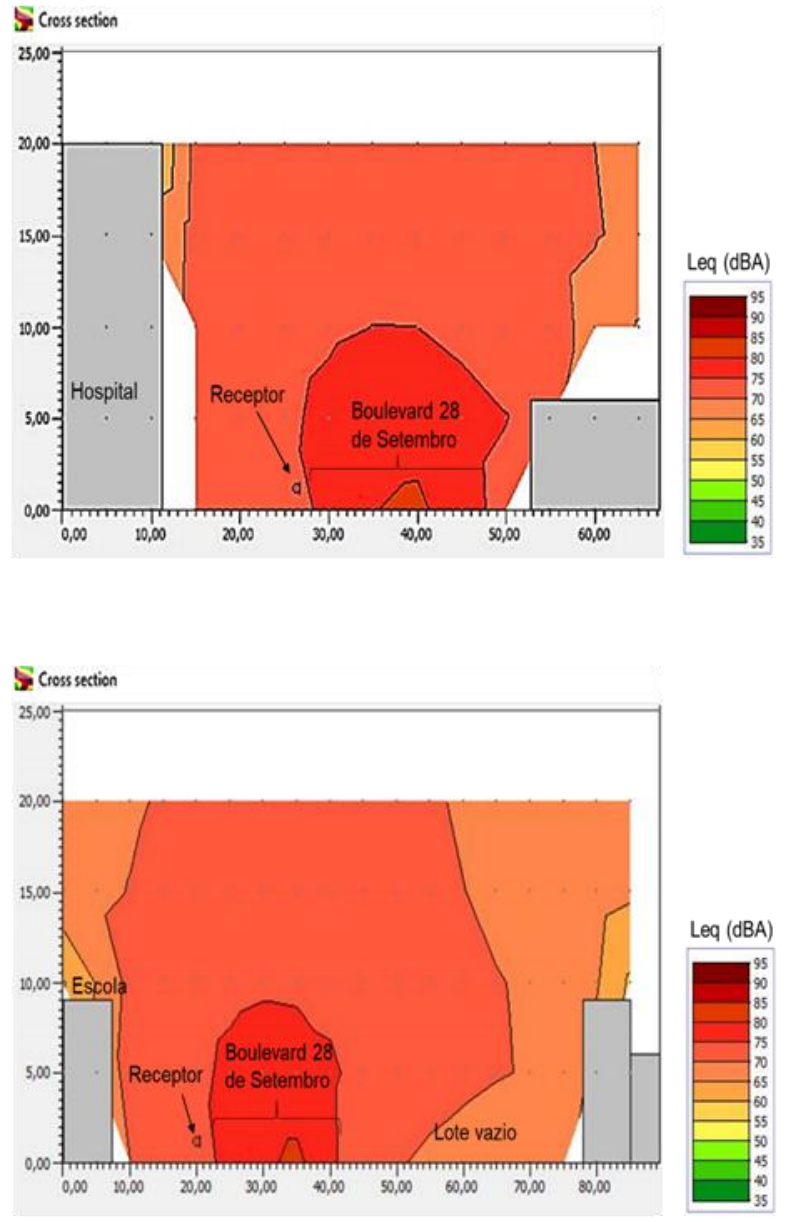

Fonte: Autoras, 2018. 
Na Figura 7, verifica-se que esse nível é superior a $65 \mathrm{~dB}$ nas fachadas principais da Escola Argentina e do Hospital Pedro Ernesto, o que pode interferir nas respectivas atividades. Também é possível observar que os níveis de pressão sonora são mais intensos conforme se aproxima no eixo da via onde se encontra a principal fonte: o tráfego de veículos.

A Figura 8 apresenta uma comparação entre os níveis medidos e os limites permitidos pela NBR 10.151, conforme Tabela 1. Para todos os pontos observa-se um excesso de ruído, especialmente nos três receptores críticos, $B, C$ e $\mathrm{H}$, onde há um excesso de mais de $20 \mathrm{~dB}$ no período diurno.

Figura 8 - Comparação entre o NCA e o nível de pressão sonora medido por ponto de medição Situação (1).

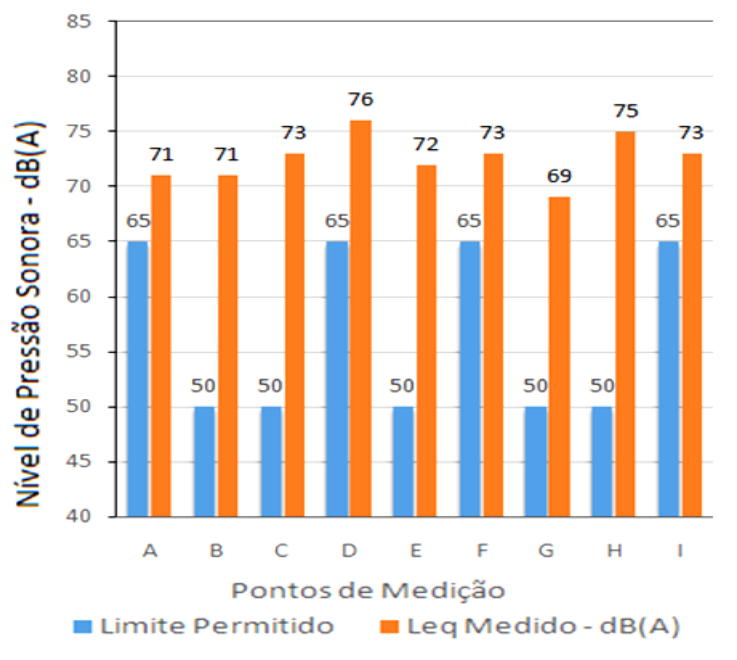

Fonte: Autoras, 2018

\subsection{Situação (2) - Escola de Samba}

A Tabela 4 apresenta os resultados obtidos nas medições feitas em campo nos cinco pontos de análise conforme Figura 6, considerando a ocorrência do evento na escola de samba como principal fonte sonora, assim como a diferença entre os valores com e sem atuação da mesma.

A partir dos dados obtidos, é possível observar que nos pontos I e J, mais sujeitos ao ruído gerado pelo tráfego de veículos, os níveis
(LAeq) sem a atuação da fonte já se encontravam muito acima do permitido. $O$ acréscimo da fonte geradora objeto do estudo impactou de forma irregular por conta de pequenas variações no fluxo de veículos no curto intervalo entre as medições do ponto $B$, uma vez que está situado em uma rua com fluxo menor.

Para os pontos $L$ e $M$, que se situam mais perto do centro da quadra e possuíam níveis próximos ao recomendado pela Norma, a atuação da fonte teve impacto significativo elevando a patamares consideravelmente superiores. A Figura 9 apresenta as diferenças entre os limites permitidos e os medidos.

Figura 9 - Comparação entre o NCA e o nível de pressão sonora medido por ponto de medição Situação (2).

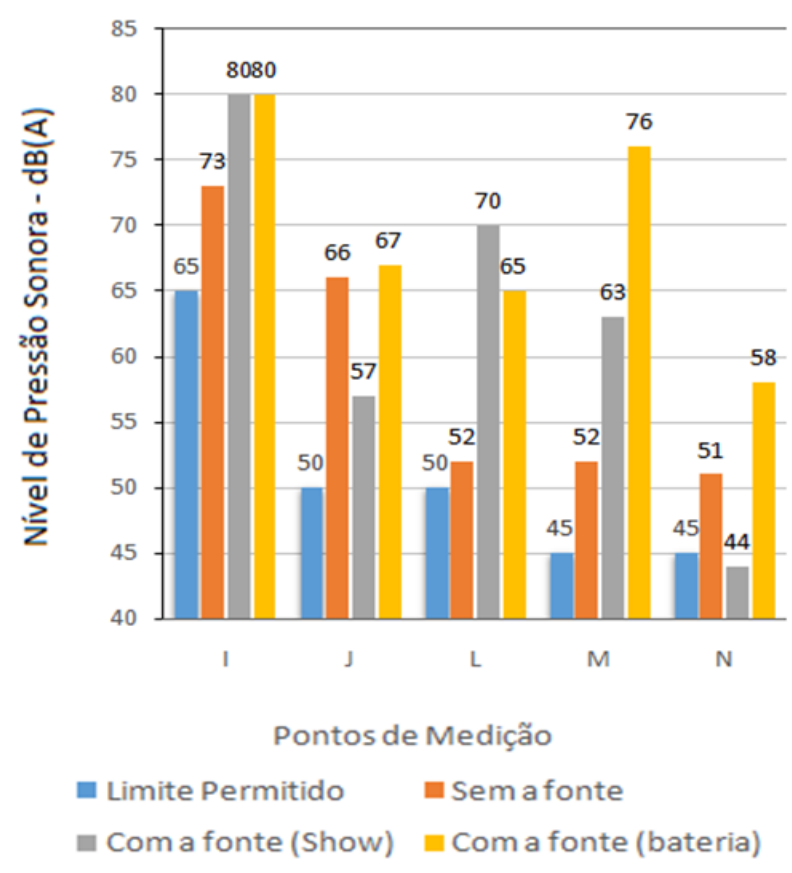

Fonte: Autoras, 2018.

\subsection{Reação da população impactada}

Baseando-se na ISO/R 1996 [23] e resultados obtidos, foi realizada uma estimativa da resposta da comunidade em relação ao ruído para as duas situações analisadas, conforme exposto na Tabela 5 adiante. 
Tabela 5 - Resultados obtidos das etapas de medição

\begin{tabular}{|c|c|c|}
\hline $\begin{array}{l}\text { Valor que o nível } \\
\text { sonoro corrigido } \\
\text { ultrapassa o nível } \\
\text { critério (dB) }\end{array}$ & Categoria & Descrição \\
\hline 0 & Nenhuma & $\begin{array}{c}\text { Não se observa } \\
\text { reação }\end{array}$ \\
\hline 5 & Pouca & $\begin{array}{l}\text { Queixas } \\
\text { esporádicas }\end{array}$ \\
\hline 10 & Média & $\begin{array}{c}\text { Queixas } \\
\text { generalizadas }\end{array}$ \\
\hline 15 & Enérgicas & $\begin{array}{c}\text { Ação } \\
\text { comunitária }\end{array}$ \\
\hline 20 & $\begin{array}{l}\text { Muito } \\
\text { Enérgicas }\end{array}$ & $\begin{array}{c}\text { Ação } \\
\text { comunitária } \\
\text { vigorosa }\end{array}$ \\
\hline
\end{tabular}

Fonte: ISO/R 1996:1971

O enquadramento feito a partir dos dados das Figuras 8 e 9, apontam que a reação esperada nos receptores críticos (escolas e hospitais) é muito enérgica. Já para a situação da Escola de Samba, espera-se que para $80 \%$ dos pontos estudados ocorram reações muito enérgicas / enérgicas.

Porém, é necessário ressaltar que esses resultados são baseados em uma norma internacional e a reação da população não está unicamente atrelada aos níveis atingidos, mas também a questões subjetivas e culturais.

\section{Considerações Finais}

A definição de vários aspectos do planejamento urbano é responsável pela construção do cenário acústico estabelecido nos grandes centros. Fatores como o uso do solo permitido, a morfologia de vias e edificações e os sistemas de transporte podem contribuir para 0 aumento da poluição sonora e consequente impacto na saúde dos habitantes.

Nas duas situações analisadas no presente estudo, foram encontrados níveis de ruído muito superiores ao permitido na legislação brasileira. No caso dos receptores críticos (hospitais e escolas), o tráfego na via onde se localizam mostrou-se o principal responsável pela extrapolação dos níveis aceitáveis. Esse fato pode ser responsável por prejudicar as atividades de aprendizagem dos alunos e recuperação de pacientes.

A localização desses receptores em uma via principal atendida por várias linhas de ônibus, poderia ser entendida como benéfica na etapa de planejamento urbano se vista unicamente pelo aspecto da acessibilidade.Todavia, sob a ótica do incômodo sonoro dos usuários, a qualidade do ambiente mostrou-se comprometida devido à sua localização.

Quanto à atividade da Escola G.R.E.S Unidos de Vila Isabel, alvo histórico de reclamações da população vizinha, foi levantado que essa não é a grande responsável pela extrapolação dos níveis de ruído na via principal, a Boulevard 28 de Setembro. Pois, esses pontos já são impactados pelo tráfego de veículos, inclusive em períodos sem atuação dessa fonte.

Entretanto, as medições e a simulação evidenciaram que, para os pontos do interior do quarteirão localizados nos fundos da quadra da escola de samba, os eventos tiveram impacto mais significativo. Nesses locais, esses eventos chegarem a ser responsáveis por alterar a situação inicial de atendimento ao recomendado para um nível de desconforto acústico.

Assim sendo, o presente estudo mostrou que a permissão de ocupação influi diretamente no cenário acústico encontrado e que o mapeamento do ruído deve considerar a contribuição de cada uma das fontes existentes. Mostrouse importante avaliar quais são as áreas onde é possível e necessário intervir em caso de fontes sonoras pontuais e quando sua contribuição não é significativa frente ao ruído já gerado comumente pelo tráfego.

\section{Referências}

[1] UNITED NATIONS HUMAN SETTLEMENTS PROGRAMME (UN-Habitat). State of the world's cities 2008/2009: Harmonious Cities. London: Earthscan; Nairobi:, 2008. Disponível em: $<$ https://unhabitat.org/books/ state-of-the- 
worlds-cities-20082009-harmonious-cities-2/>. Acesso em:09 abril 2018.

[2] BRASIL. Perda auditiva induzida por ruído (PAIR). Brasília: Editora do Ministério da Saúde. 2006.

[3] WORLD HEALTH ORGANIZATION (WHO). Guidelines for comunity noise. Edited by Birgitta Berghund, Thomas Lindvall, Dietrich H. Schela. 1999.Disponível em: <http://www.who.int/iris/ handle/10665/66217>. Acesso em: 07 abril 2018

[4] LACERDA, Adriana Bender Moreira et al. Ambiente urbano e percepção da poluição sonora. Ambiente \& Sociedade, v. 8, n. 2, 2005.

[5] HAMMER, M.S.; SWINBURN, T. K.; NEITZEL, R. L. Environmental noise pollution in the Unites States: developing aneffective public health response. Environ Health Perspect. 122: 115-119. 2014. Disponível em: http://dx.doi.org/10.1289/ehp.1307272.

[6] KANG, J. Urban sound environment. 1a edição. Taylor and Francis. New York, 2007.

[7] OLIVEIRA, M. P. G.; MEDEIROS E. B.; DAVIS JR., C. A. Planejando o Meio ambiente Acústico Urbano: uma abordagem baseada em SIG. Revista IP - Informática Pública. Belo Horizonte, v. 2, n. 1, p. 81-96. Disponível em: <http://www.ip.pbh.gov.br/ANO2_N1_PDF/ ip0201piedade.pdf >. Acesso em: 15 ago. 2007.

[8] PEREIRA, N.; FONSECA, R.; LOPES, A. Relatório final: mapas de ruído do conselho da Marinha Grande. Portugal. ECO 14, Lda. Laboratório de acústica e vibrações. 2004. Disponível em: <https://www.cm-mgrande. pt/> . Acesso em: 17 agosto. 2018.

[10]ZAJARKIEWICCH, D. F. B. Poluição Sonora: principais fontes. Aspectos Jurídicos e técnicos. Dissertação de Mestrado. São Paulo. Pontifícia Universidade Católica de São Paulo. 2010.
[11] NIEMEYER, M. L.; SANTOS, M. J. O. Qualidade Acústica no Espaço Urbano, 2001.

[12] DINTRANS, A; PRÉNDEZ, M. A method of assessing measures to reduce road traffic: a case study in Santiago, Chile. Applied Acoustics, v.74, n. 12, p. 1486-1491, dez. 2013.

[13] MASCHKE, C. Preventive Medical Limits for Chronic Traffic Noise Exposure. Acústica 1999.

[14] ZANNIN, PHT; CALIXTO, A.; DINIZ, F.B.; FERREIRA, J.A.; SCHULI, R.B. Incômodo causado pelo ruído urbano à população de Curitiba, PR. Rev. Saúde Pública 2002.

[15] KOHLER, R.; SPECHT, L.P; BROZATTI, G.D. Ruído causado pelo transporte ferroviário em um segmento urbano: estudo do caso da cidade de ljuí-RS. Teoria e Prática na Engenharia Civil, 2012.

[16] GREY, G.; DENEKE, F. J. Urban forestry. 2. ed. Nova York: John Wiley \& Sons, 1986.

[17] COUTRO, E. M.; MIRANDA, G. M. Levantamento da arborização urbana de Irati PR e sua influência na qualidade de vida de seus habitantes. In: Revista eletrônica. Lato Sensu ano 2, no 1, julho de 2007.

[18] DIRECTIVE 2002/49/EC. Environmental Noise Directive. 2002. Disponível em: <http://eur-lex.europa.eu/legal-content/ EN/TXT/PDF/?uri= CELEX:32002L0049\&from=EN>. Acesso em:07 abril 2018.

[19] CALIXTO, A. O ruído gerado pelo tráfego de veículos em "rodovias-grandes avenidas" situadas dentro do perímetro urbano de Curitiba: analisado sob parâmetros acústicos objetivos e seu impacto ambiental. Dissertação de mestrado. Universidade Federal do Paraná, Curitiba. 2002. 
[20] MARDONES, M. D. M. Mapeamento dos níveis de ruído em Copacabana, Rio de Janeiro, através de simulação computacional. Dissertação de mestrado. COPPE, Universidade Federal do Rio de Janeiro, Rio de Janeiro. 2009.

[21] GUEDES, I. C. M.; BERTOLI, S. R. Mapa Acústico como ferramenta de avaliação de ruído de tráfego veicular em Aracajú - Brasil. PARC Pesquisa em Arquitetura e Construção, Campinas, v. 5, n. 2, p. 40-51, jul./dez. 2014.

[22] Associação Brasileira de Normas Técnicas. NBR 10151 - Procedimento para avaliação de ruído em áreas habitadas visando o conforto da comunidade (2000)

[23] INTERNATIONAL ORGANIZATION FOR STANDARDIZATION. ISO/R 1996:1971 - Noise with respect to human beings

*Camilla França e Daniela Rocha são mestrandas do Programa de Engenharia Urbana (PEU/POLIUFRJ) 


\section{ANEXO A}

Figura 2 - Área de estudo e localização dos receptores sonoros críticos na Boulevard 28 de Setembro.

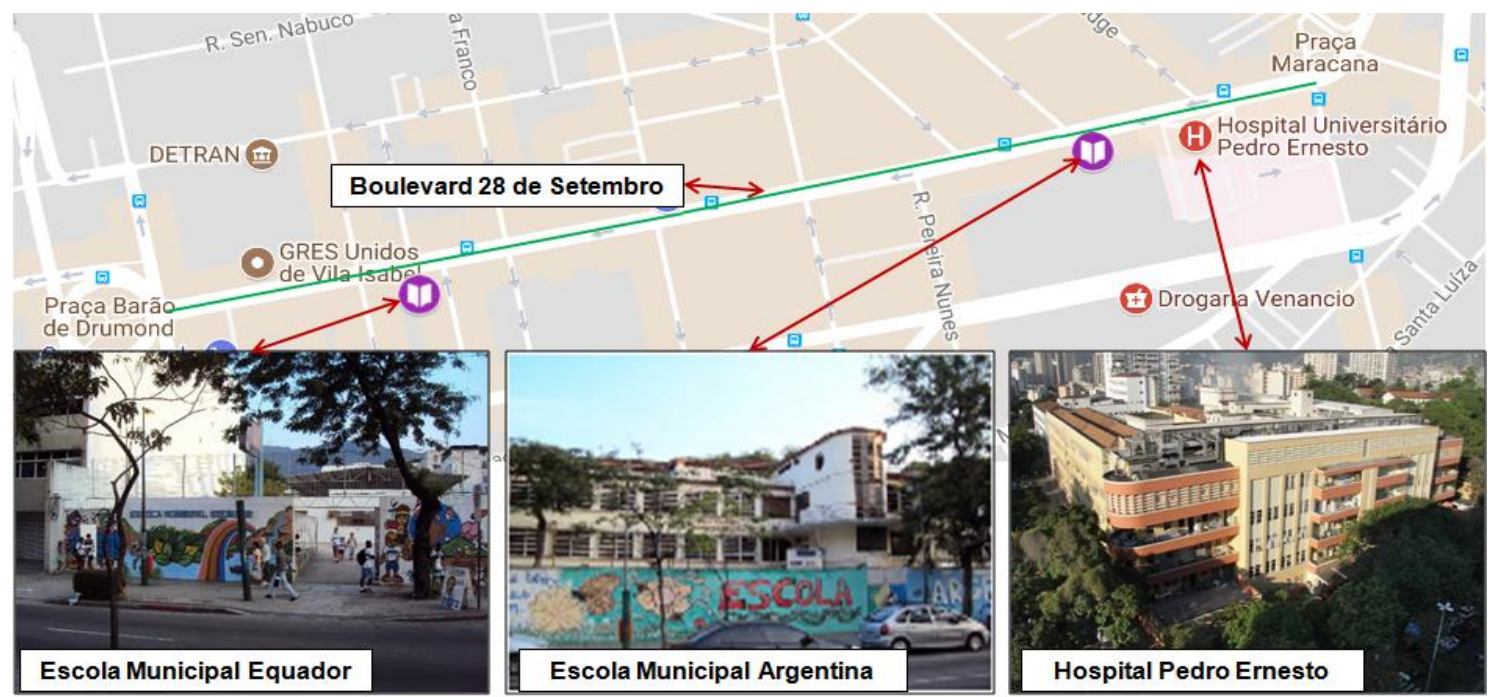

Fonte: Adaptado de Google Maps, 2018. 
ANEXO B

Figura 4 - Pontos de medição de níveis de pressão sonora - Situação (A) e (B).

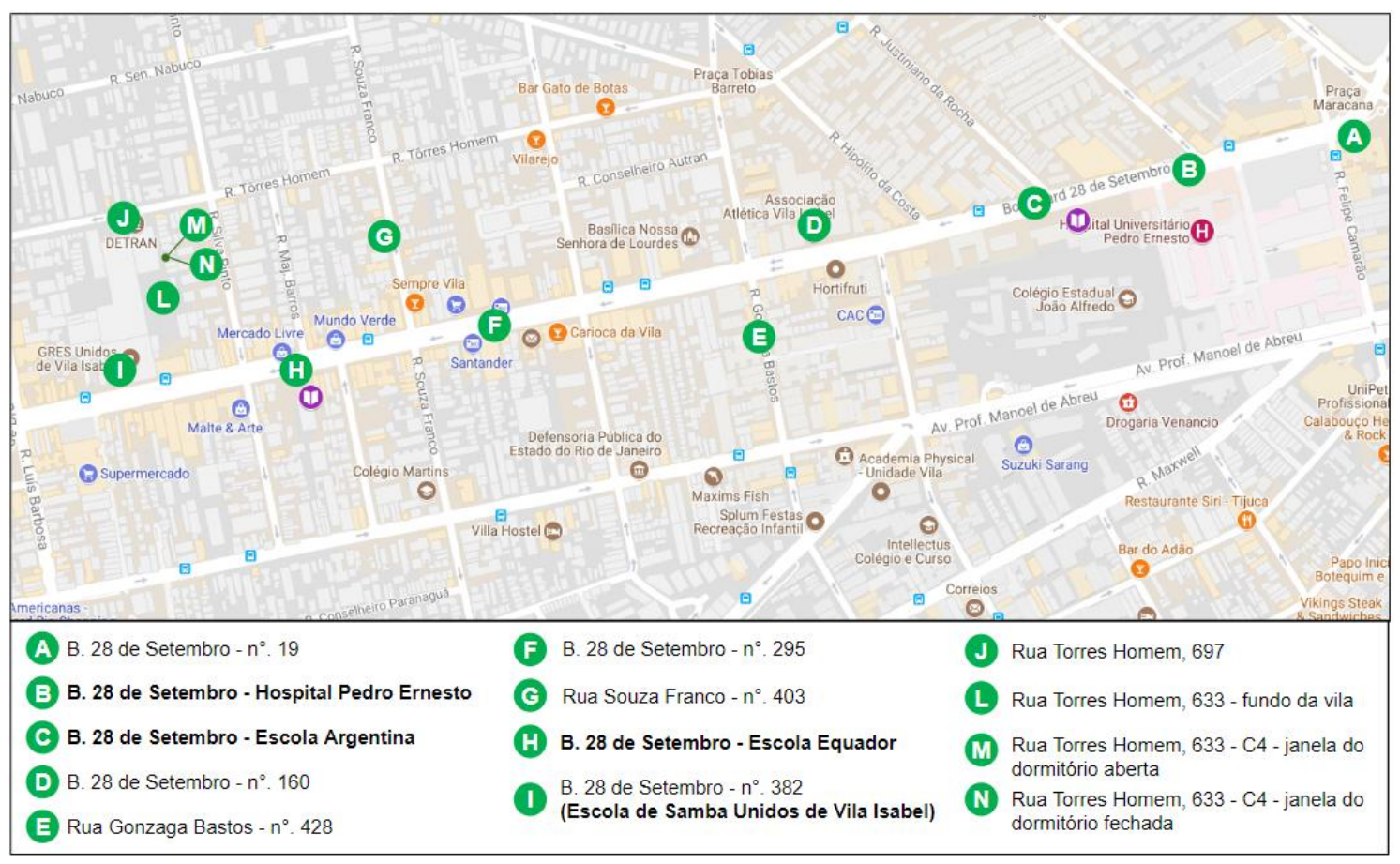

Fonte: Elaboração Autoras a partir do Google Maps, 2018 